\title{
Solid-Liquid Phase Diagram of the Binary System Octadecanoic Acid and Octadecanol and the Thermal Chemical Property of the Composition at Eutectic Point
}

\author{
Can Liu, Kaiyu Zhao, Yafei Guo $\mathbb{D}$, Liping Guo, and Tianlong Deng \\ Tianjin Key Laboratory of Marine Resources and Chemistry, College of Chemical Engineering and Materials Science, \\ Tianjin University of Science and Technology, Tianjin 300457, China \\ Correspondence should be addressed to Yafei Guo; guoyafei@tust.edu.cn and Tianlong Deng; tldeng@tust.edu.cn
}

Received 29 April 2020; Revised 15 June 2020; Accepted 17 August 2020; Published 2 September 2020

Academic Editor: João Paulo Leal

Copyright (C) 2020 Can Liu et al. This is an open access article distributed under the Creative Commons Attribution License, which permits unrestricted use, distribution, and reproduction in any medium, provided the original work is properly cited.

\begin{abstract}
Phase diagram is a powerful tool to guide the exploitation of thermal energy materials. Heat storage technology of phase-change material (PCM) was widely used to solve major energy utilization problems on large energy consumption and low utilization efficiency. In this work, a novel solid-liquid phase diagram of the binary system octadecanoic acid $\left(\mathrm{C}_{18^{-}}\right.$-acid $)+$octadecanol $\left(\mathrm{C}_{18^{-}}\right.$ $\mathrm{OH}$ ) was investigated using the differential scanning calorimeter (DSC). The phase-change temperature and phase-change enthalpies against the composition of $\mathrm{C}_{18}$-acid and $\mathrm{C}_{18}-\mathrm{OH}$ were determined experimentally, and then the binary phase diagram of $T-X$ ( $X$ expresses the mass fraction of $\mathrm{C}_{18}-\mathrm{OH}$ in the two components of $\mathrm{C}_{18}$-acid and $\mathrm{C}_{18^{-}} \mathrm{OH}$ ) was established for the first time. The phase diagram belongs to a binary simple system with one eutectic point, and the content of $\mathrm{C}_{18}-\mathrm{OH}$ at eutectic point is 0.4 in mass fraction. Neither solid solution nor copolymer was formed. The thermal chemical properties on the phase-change latent heat $(Q)$, phase-change temperature $\left(T_{\mathrm{p}}\right)$, and the thermal conductivity $(\lambda)$ for the composition at the eutectic point of the binary system are $198.7 \mathrm{~J} \cdot \mathrm{g}^{-1}, 44.2^{\circ} \mathrm{C}$, and $0.2352 \mathrm{~W} \cdot \mathrm{m}^{-1} \cdot \mathrm{K}^{-1}$, respectively. This result indicates that the material at eutectic point has a great potential to be used as energy storage material for supply of heat and scouring bath.
\end{abstract}

\section{Introduction}

As the rising demand for energy from the growing population, the fossil fuels have been largely consumed, which seriously caused the environmental pollution and emission of greenhouse gases into the atmosphere [1]. As a consequence, a variety of renewable energy sources, such as wind, solar, tidal, geothermal, and hydrothermal energy, have been developed by providing large energy reserves and reversible energy generation by reducing of gas emissions $[2,3]$. Although renewable sources of energy such as solar energy are considered the most promising renewable energy sources, there are also some limitations, such as intermittent (because solar lighting is not available at night) and uncertainty (climate dependence) [4]. In order to avoid these limitations, the sustainable, reliable, and efficient energy storage systems have been developed as energy reserves. The occurrence of phase-change materials (PCMs) provides a suitable settlement for the problem of intermittent solar energy $[5,6]$.

Phase-change materials (PCMs) have many attractive characteristics, such as high storage density in a small temperature region, compact energy storage systems under isothermal conditions, and high heat of fusion, which are considered to be the most effective methods actively pursued. In the pure temperature range, the PCM is able to hoard or release a large amount of latent heat during solidliquid, liquid-gas, or solid-solid phase transformation [7]. PCMs were widely used for different heating (or cooling) functions in buildings, heat insulation panels for electronic products, power generation system, temperature controlling textiles, solar photovoltaic, and food storage for their excellent characteristics [8-13]. On the basis of the chemical properties of PCM, they are divided into inorganic and organic PCM [14]. Inorganic PCM shows good flame 
retardancy, high thermal conductivity, high heat of fusion, and large volume heat storage density $\left(250-400 \mathrm{~kg} \cdot \mathrm{dm}^{-3}\right)$ [15], due to the poorly cyclic stability of inorganic PCMs; the organic PCMs received tremendous attention nowadays for their advantages of high energy storage density, small corrosivity, no (or slight) supercooling, and no phase segregation on the application of thermal cycles [8]. However, using individual organic material for preparation has a limitation to realize the comfort temperature demands such as heating/cooling of buildings and textiles due to their fixed phase transition temperature. These problems could be solved through blending two or more organic components, until each of the components would have one sharp melting and freezing peak temperatures, and eutectic temperature [16]. Zhao et al. [17] reported a series of binary eutectic fatty acids and revealed a reasonable thermal performance on TES applications. Li et al. [18] plotted a phase diagram for a sequence of binary and ternary eutectic fatty acids derived from four organic PCMs (stearic acid, palmitic acid, myristic acid, and lauric acid) and revealed their phase-change transition properties. However, the organic $\mathrm{PCMs}, \mathrm{C}_{18}$-acid and $\mathrm{C}_{18} \mathrm{-OH}$ mixtures, have not been reported in the references.

In this work, a novel solid-liquid eutectic composite material prepared by $\mathrm{C}_{18}$-acid and $\mathrm{C}_{18^{-}} \mathrm{OH}$ was developed using DSC. The phase-change temperature and phasechange enthalpies against the composition of $\mathrm{C}_{18}$-acid and $\mathrm{C}_{18}-\mathrm{OH}$ were determined experimentally, and then the binary phase diagram of $\mathrm{C}_{18}$-acid and $\mathrm{C}_{18}-\mathrm{OH}$ was established. The phase diagram belongs to a binary simple system with one eutectic point, and thermal performances of the eutectic point such as phase-change temperature, latent heat, and thermal conductivity were investigated systematically.

\section{Experiment}

2.1. Reagents and Apparatus. The analytical reagents used in this experiment are listed in Table 1 and have not been further purified.

The differential scanning calorimeter (DSC 200 F3, Netzsch Instrument Inc., Germany) was used to measure the melting temperatures with an uncertainty of $\pm 0.01 \mathrm{~K}$ as well as latent heat of phase-change materials with an uncertainly of $\pm 0.2 \mathrm{~J} \cdot \mathrm{g}^{-1}$. The thermal conductivity analyzer (TC3000E, Xi'an Xiaxi Electronic Technology Co., Ltd, China) is a thermal conductivity tester with a transient hot-line method with the accuracy within $3 \%$. The weight was measured by the analytical balance (AL204, Mettler-Toledo Instruments (Shanghai) Co., Ltd. China) with an accuracy of $0.1 \mathrm{mg}$ and a weighing range from 0 to $210 \mathrm{~g}$. The Fourier transform infrared spectrometer (FT-IR, Tensor 27, Brooke Optics, Germany) was used to infer the structure of compounds with the resolution of 1 to $0.4 \mathrm{~cm}^{-1}$ and the absorption accuracy of $0.01 \%$.

2.2. Synthesis of PCMs. The PCMs were prepared using $\mathrm{C}_{18^{-}}$ acid and $\mathrm{C}_{18} \mathrm{-OH}$ as the based materials with different mass ratio. The solid compositions of $\mathrm{C}_{18}$-acid and $\mathrm{C}_{18}-\mathrm{OH}$ with different proportions were heated to completely melt at $80^{\circ} \mathrm{C}$ in an oil bath and then stirred for 10 minutes. The PCMs were finally obtained by cooling down to the room temperature.

2.3. Latent Heat Analysis. The phase-change temperature and enthalpies against the different composition of $\mathrm{C}_{18}$-acid and $\mathrm{C}_{18} \mathrm{OH}$ were determined to establish solid-liquid phase diagram of the binary system $\mathrm{C}_{18}$-acid and $\mathrm{C}_{18}-\mathrm{OH}$. On the basis of the ASTM D2766-09 and E792-06 standard test methods, the differential scanning calorimeter (DSC 200 F3, Netzsch Instrument Inc., Germany) was used to test specific heat, melting, and crystallizing enthalpies (latent heat) of the binary subsystem [19-22]. In this work, samples were heated and cooled between 5 and $80^{\circ} \mathrm{C}$ at a rate of $10 \mathrm{~K} \cdot \mathrm{min}^{-1}$ $[23,24]$. The temperature and enthalpy were calibrated using a series of standard materials including naphthalene, indium, tin, lead, and zinc under an inert argon atmosphere at $20 \mathrm{ml} \cdot \mathrm{min}^{-1}$. Then, the DSC heating and cooling curves were obtained. In order to prevent the influence of uneven distribution of samples in the crucible, each composition was tested in triplicate, and the average was taken.

2.4. Thermal Conductivity Test. The transient probe method [25] was selected to measure the thermal conductivities of PCM with the temperature of $27^{\circ} \mathrm{C}$ and the relative humidity (RH) of $41 \%$ by using the thermal conductivity analyzer with the accuracy of $1 \%$. Experiment was carried out three times continuously, and the average value was taken. The conductivity as a function of temperature and time can be expressed as follows:

$$
\lambda=\frac{q \cdot \ln \left(t_{2} / t_{1}\right)}{4 \pi\left(T_{2}-T_{1}\right)},
$$

where $\lambda$ is the thermal conductivity of the sample tested; $q$ is the generated heat per unit length of the sample/time; $t_{1}$ and $t_{2}$ are the onset and final measured time lengths; and $T_{1}$ and $T_{2}$ are the temperatures at $t_{1}$ and $t_{2}$, respectively.

2.5. Fourier Infrared Characterization. The FT-IR was used to infer the structure of compounds with the resolution of 1 to $0.4 \mathrm{~cm}^{-1}$ as well as the absorption accuracy of \pm 0.0001 . The dried phase-change material and $\mathrm{KBr}$ were ground at a mass ratio of 1:100; after that, the material was pressed into a transparent sheet at $8-10 \mathrm{MPa}$ and subjected to infrared spectroscopy in the range of $400-4000 \mathrm{~cm}^{-1}$.

\section{Results and Discussion}

3.1. Phase Diagram of Binary System $\mathrm{C}_{18^{-}} \mathrm{Acid}+\mathrm{C}_{18^{-}} \mathrm{OH}$. Figure 1 shows the comparison of heating and cooling DSC curves of the $\mathrm{C}_{18}$-acid $+\mathrm{C}_{18}-\mathrm{OH}$ binary system with different mass ratios.

$\mathrm{C}_{18}-\mathrm{OH}$ has two different crystal forms, and $\mathrm{C}_{18}$-acid has three different crystal forms of A, B, and C $[26,27]$. The melting points between the different crystal forms of the two substances are very close [28]. Therefore, there is a solid- 
TABLE 1: Chemicals used in this work.

\begin{tabular}{lccc}
\hline Regent & Sources & CAS reg. no. & Purity in mass fraction \\
\hline $\mathrm{C}_{18}$-acid & Tianjin Guangfu Development Co., Ltd. & $57-11-4$ & $\geq 0.980$ \\
$\mathrm{C}_{18} \mathrm{OH}$ & Tianjin Ketong Chemical Reagent Co., Ltd. & $112-92-5$ & $\geq 0.990$ \\
\hline
\end{tabular}

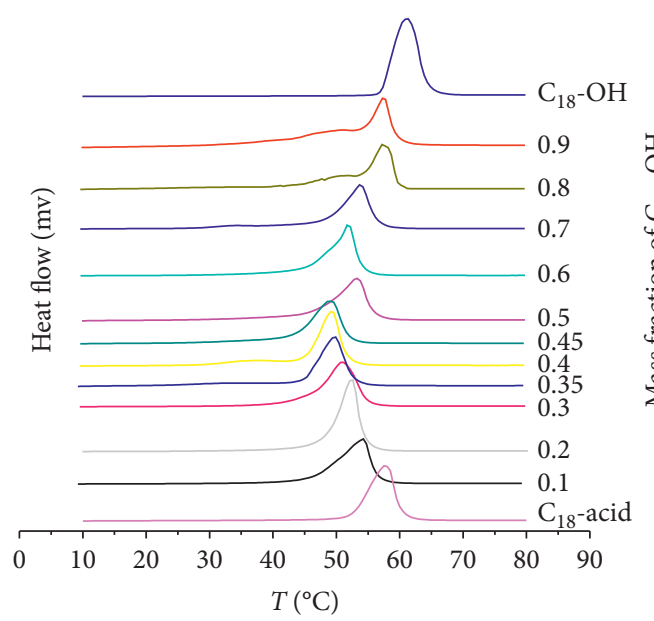

(a)

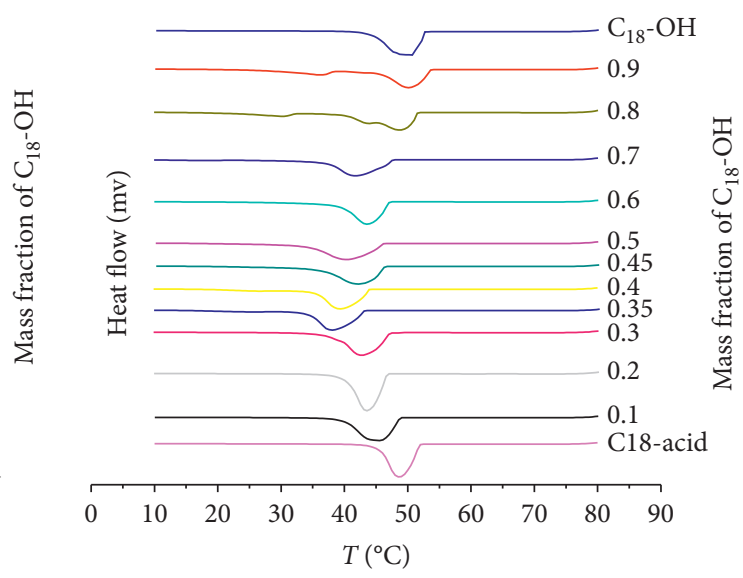

(b)

Figure 1: Comparison of heating (a) and cooling (b) DSC curves of the binary system of $\mathrm{C}_{18}$-acid and $\mathrm{C}_{18}$-OH.

TABLE 2: Temperatures and enthalpies of melting of the binary system of $\mathrm{C}_{18}$-acid $+\mathrm{C}_{18}-\mathrm{OH}$ (from the heating scan) ${ }^{\mathrm{a}}$.

\begin{tabular}{|c|c|c|c|c|c|c|c|}
\hline \multirow{2}{*}{ Mass fraction $\left(\mathrm{C}_{18}-\mathrm{OH}\right)$} & \multicolumn{3}{|c|}{ Temperature, $T_{p}\left({ }^{\circ} \mathrm{C}\right)$} & \multicolumn{3}{|c|}{ Peak enthalpy $\left(\mathrm{J} \cdot \mathrm{g}^{-1}\right)$} & \multirow{2}{*}{ Total enthalpy $\left(\mathrm{J} \cdot \mathrm{g}^{-1}\right)$} \\
\hline & First & Second & Third & First & Second & Third & \\
\hline 0.00 & 52.6 & - & - & 203.3 & - & - & 203.3 \\
\hline 0.10 & 50.1 & - & - & 193.9 & - & - & 193.9 \\
\hline 0.20 & 48.6 & - & - & 223.7 & - & - & 223.7 \\
\hline 0.30 & 47.1 & - & - & 183.4 & - & - & 183.4 \\
\hline 0.35 & 45.6 & - & - & 157.0 & - & - & 157.0 \\
\hline 0.40 & 44.2 & - & - & 198.7 & - & - & 198.7 \\
\hline 0.45 & 45.8 & - & - & 171.5 & - & - & 171.5 \\
\hline 0.50 & 47.9 & - & - & 213.5 & - & - & 213.5 \\
\hline 0.60 & 49.8 & - & - & 200.2 & - & - & 200.2 \\
\hline 0.70 & 51.5 & - & - & 213.2 & - & - & 213.2 \\
\hline 0.80 & 53.2 & - & - & 203.4 & - & - & 203.4 \\
\hline 0.90 & 55.0 & - & - & 43.9 & 138.7 & - & 182.6 \\
\hline 1.00 & 57.2 & - & - & 254.6 & - & - & 254.6 \\
\hline
\end{tabular}

The differential scanning calorimeter was employed in the measurement with an uncertainty of $\pm 0.01 \mathrm{~K}$ as well as latent heat with an uncertainly of $\pm 0.2 \mathrm{~J} \cdot \mathrm{g}^{-1}$.

solid transition in the two substances during the melting process and both of them have a large melting range and a wide peak shape as shown in Figure 1(a).

The temperatures of the peak of the endotherms and enthalpies extracted from Figure 1(a) are listed in Table 2.

Taking the phase-change temperature as the longitudinal coordinate and the mass fraction of $\mathrm{C}_{18}-\mathrm{OH}$ as the transverse coordinate, the solid-liquid phase diagram of the binary system $\left(\mathrm{C}_{18}\right.$-acid $\left.+\mathrm{C}_{18}-\mathrm{OH}\right)$ is shown in Figure 2 .

It could clearly see from Figure 2 that the binary system $\left(\mathrm{C}_{18}\right.$-acid $\left.+\mathrm{C}_{18}-\mathrm{OH}\right)$ was considered as a simple eutectic system, and the melting point decreased with the increasing of the mass fraction of $\mathrm{C}_{18}-\mathrm{OH}$ at the beginning. However, when the mass fraction of $\mathrm{C}_{18}-\mathrm{OH}$ reaches 0.4 , the melting point of the system increases with the rise of the mass fraction of $\mathrm{C}_{18}-\mathrm{OH}$. The phase-change material with the lowest eutectic point has a short melting range, a stable melting point, and the composition not changed with temperature [29-32]. It indicated that the phase diagram belong to a binary simple system with one eutectic point, and the content of $\mathrm{C}_{18}-\mathrm{OH}$ at eutectic point is 0.4 in mass fraction. It can be seen from Table 2 that the phase-change 


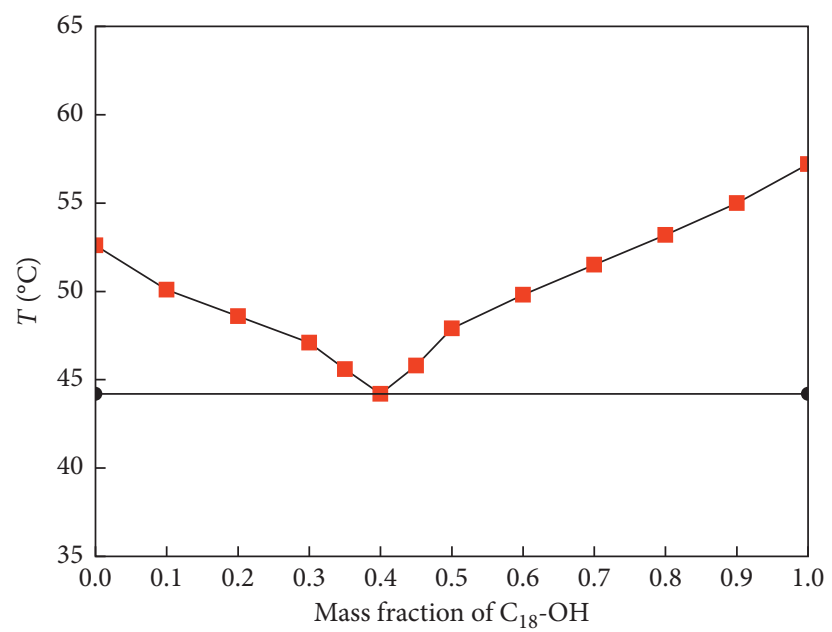

Figure 2: Phase diagram of the binary system $\left(\mathrm{C}_{18}-\mathrm{OH}+\mathrm{C}_{18}\right.$-acid $)$.

TABle 3: Comparison of the melting temperature (from the second heating scan) between the experimental and calculated values ${ }^{\mathrm{a}}$.

\begin{tabular}{|c|c|c|c|}
\hline \multirow{2}{*}{ Mass fraction $\left(\mathrm{C}_{18}-\mathrm{OH}\right)(\%)$} & \multicolumn{2}{|c|}{ Temperature, $T_{p}\left({ }^{\circ} \mathrm{C}\right)$} & \multirow{2}{*}{$\Delta T^{\mathrm{b}}\left({ }^{\circ} \mathrm{C}\right)$} \\
\hline & Experiment value & Calculated value & \\
\hline 0 & 52.6 & 52.6 & 0 \\
\hline 10 & 50.1 & 50.9 & 0.8 \\
\hline 20 & 48.6 & 49.1 & 0.5 \\
\hline 30 & 47.1 & 47.0 & 0.1 \\
\hline 35 & 45.6 & 45.9 & 0.4 \\
\hline 40 & 44.2 & 44.7 & 0.5 \\
\hline 45 & 45.8 & 47.3 & 1.5 \\
\hline 50 & 47.9 & 48.6 & 0.7 \\
\hline 60 & 49.8 & 50.8 & 1 \\
\hline 70 & 51.5 & 52.7 & 1.2 \\
\hline 80 & 53.2 & 54.4 & 1.2 \\
\hline 90 & 55.0 & 55.9 & 0.9 \\
\hline 100 & 57.2 & 57.2 & 0 \\
\hline
\end{tabular}

${ }^{a}$ The differential scanning calorimeter was employed in the measurement with an uncertainty of $\pm 0.01 \mathrm{~K}$ as well as latent heat with an uncertainly of $\pm 0.2 \mathrm{~J} \cdot \mathrm{g}^{-1}$;

${ }^{\mathrm{b}} \Delta T$ is the absolute value of the difference between the experimental temperature and the calculated temperature.

temperature and phase-change latent heat at the eutectic point are $44.2^{\circ} \mathrm{C}$ and $198.7 \mathrm{~J} \cdot \mathrm{g}^{-1}$, respectively.

The liquids of the binary system can be calculated by Schroeder formula [33] (formula (2)), and the experimental and calculated results are shown in Table 3 and plotted in Figure 3:

$$
\operatorname{Ln} x=\frac{\Delta H_{\mathrm{m}}}{R}\left(\frac{1}{T_{\mathrm{m}}}-\frac{1}{T}\right) .
$$

It can be seen from Table 3 and Figure 3 that the calculated temperature of phase transition at eutectic point is $0.5^{\circ} \mathrm{C}$ higher than that of the experimental value. Moreover, the difference between the calculated value and the experimental value also increases with the increase of the mass fraction of $\mathrm{C}_{18} \mathrm{-OH}$, which may be due to the existence of solid-solid phase transition.

The pure materials of $\mathrm{C}_{18}$-acid and $\mathrm{C}_{18}-\mathrm{OH}$ and the phase transition materials at the lowest eutectic point were characterized by infrared spectroscopy. It can be seen from Figure 4 that there is no new bond at the lowest eutectic

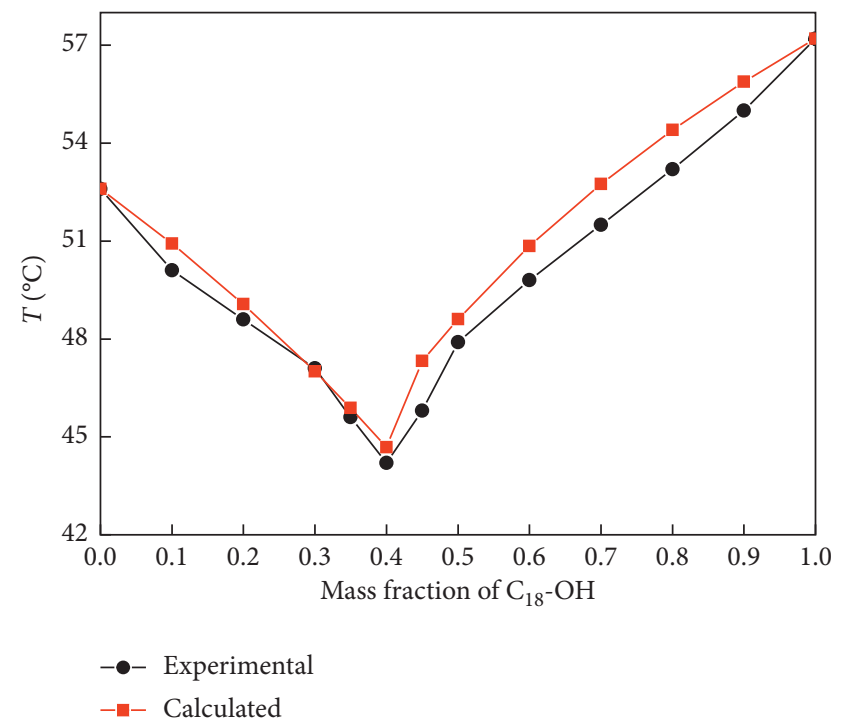

FIGURE 3: Comparison of phase diagrams between the calculated and experimental values. 


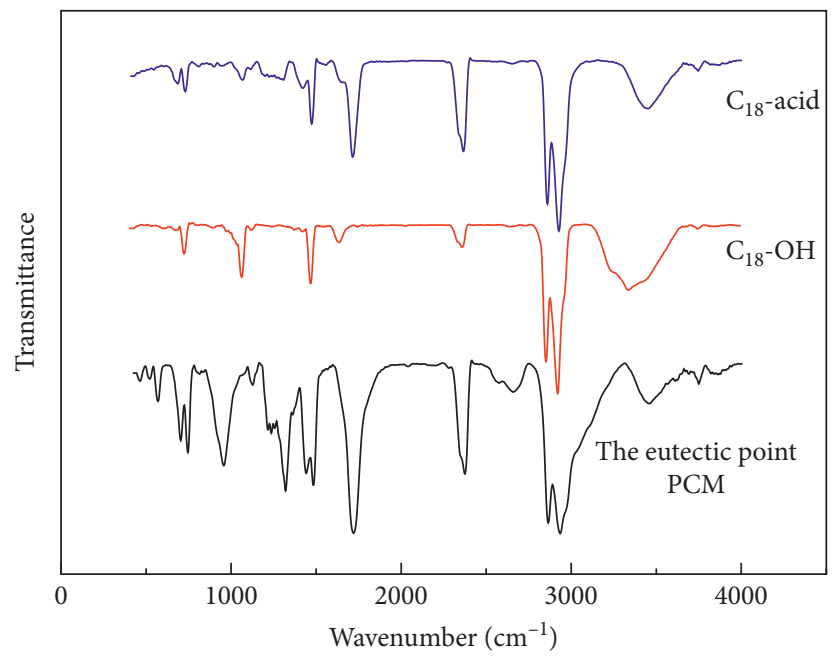

Figure 4: FT-IR spectrum of $\mathrm{C}_{18}$-acid, $\mathrm{C}_{18}-\mathrm{OH}$, and the eutectic point PCM.

TABle 4: Thermal conductivity of PCM at the eutectic point ${ }^{\mathrm{a}}$.

\begin{tabular}{lccc}
\hline Sample name & $\begin{array}{c}\text { Test temperature, } \\
T\left({ }^{\circ} \mathrm{C}\right)\end{array}$ & $\begin{array}{c}\lambda \\
\left(\mathrm{W} \cdot \mathrm{m}^{-1} \cdot \mathrm{K}^{-1}\right)\end{array}$ & $\begin{array}{c}\bar{\lambda} \\
\left(\mathrm{W} \cdot \mathrm{m}^{-1} \cdot \mathrm{K}^{-1}\right)\end{array}$ \\
\hline Phase-change & 31.51 & 0.2353 & \\
material & 31.50 & 0.2347 & 0.2352 \\
& 31.46 & 0.2356 & \\
\hline
\end{tabular}

${ }^{\text {a }}$ The thermal conductivity tester was employed in the measurement with an accuracy of $3 \%$.

point of the $\mathrm{C}_{18}$-acid- $\mathrm{C}_{18}-\mathrm{OH}$ binary system, and the binding mode of the two materials is physical combination. Neither solid solution nor copolymer formed.

\subsection{Thermal Conductivity Test of the Eutectic Point PCM.} The thermal conductivity of the eutectic point PCM was tested three times continuously, and the average value was taken. It can be seen from Table 4 that the thermal conductivity coefficient of the phase-change material is $0.2352 \mathrm{~W} \cdot \mathrm{m}^{-1} \cdot \mathrm{K}^{-1}$.

\section{Conclusion}

A novel solid-liquid eutectic composite material prepared by $\mathrm{C}_{18}$-acid and $\mathrm{C}_{18}-\mathrm{OH}$ was developed in this work. As the advantages of cheap, environmental protection, high energy storage density, small corrosivity, stable performance and not easy to appear phase separation, and supercooling, $\mathrm{C}_{18}$-acid and $\mathrm{C}_{18}-\mathrm{OH}$ were used as raw materials and mixed in different proportion and then the melting phase diagram was drawn. According to the phase diagram, it belongs to a binary simple system with the lowest eutectic point. As a result, the content of $\mathrm{C}_{18}-\mathrm{OH}$ at eutectic point is 0.4 in mass fraction. After, the thermal properties including phase-change temperature, latent heat, and thermal conductivity of the eutectic point PCM were investigated. The results show that the eutectic point PCM has a phase-change temperature of $44.2^{\circ} \mathrm{C}$, a latent heat of $198.7 \mathrm{~J} \cdot \mathrm{m}^{-1} \cdot \mathrm{K}^{-1}$, and a thermal conductivity of $0.2352 \mathrm{~W} \cdot \mathrm{m}^{-1} \cdot \mathrm{K}^{-1}$. All these thermal properties demonstrated that the material at eutectic point has a great potential to be used as energy storage material for supply of heat and scouring bath.

\section{Data Availability}

The data used to support the findings of this study are available from the corresponding author upon request.

\section{Conflicts of Interest}

The authors declare that they have no conflicts of interest.

\section{Acknowledgments}

Financial supports from the National Natural Science Foundation of China (21773170), the Key Projects of Natural Science Foundation of Tianjin (18JCZDJC10040), and the Yangtze Scholars and Innovative Research Team in Chinese University (IRT_17R81) are acknowledged.

\section{References}

[1] L. Qiu, Y. Ouyang, Y. Feng, and X. Zhang, "Review on micro/ nano phase change materials for solar thermal applications," Renewable Energy, vol. 140, pp. 513-538, 2019.

[2] S. Valizadeh, M. Ehsani, and M. Torabi Angji, "Development and thermal performance of wood-HPDE- PCM nanocapsule floor for passive cooling in building," Energy Sources, Part A: Recovery, Utilization, and Environmental Effects, vol. 41, no. 17, pp. 2114-2127, 2019.

[3] M. Li and C. Wang, "Preparation and characterization of GO/ PEG photo-thermal conversion form-stable composite phase change materials," Renewable Energy, vol. 141, pp. 1005-1012, 2019.

[4] S. Peng, J. Huang, T. Wang, and P. Zhu, "Effect of fumed silica additive on supercooling, thermal reliability and thermal stability of $\mathrm{Na}_{2} \mathrm{HPO}_{4} \cdot 12 \mathrm{H}_{2} \mathrm{O}$ as inorganic PCM," Thermochimica Acta, vol. 675, pp. 1-8, 2019.

[5] M. Sheikholeslami and O. Mahian, "Enhancement of PCM solidification using inorganic nanoparticles and an external magnetic field with application in energy storage systems," Journal of Cleaner Production, vol. 215, pp. 963-977, 2019. 
[6] Y. Zhong, B. Zhao, J. Lin et al., "Encapsulation of hightemperature inorganic phase change materials using graphite as heat transfer enhancer," Renewable Energy, vol. 133, pp. 240-247, 2019.

[7] N. Sarier and E. Onder, "Organic phase change materials and their textile applications: an overview," Thermochimica Acta, vol. 540, p. 7, 2012.

[8] A. Sharma, V. V. Tyagi, C. R. Chen, and D. Buddhi, "Review on thermal energy storage with phase change materials and applications," Renewable Sustainable Energy Review, vol. 13, p. 318, 2009.

[9] A. A. Al-Abidi, S. Bin Mat, K. Sopian, M. Y. Sulaiman, C. H. Lim, and A. Th, "Review of thermal energy storage for air conditioning systems," Renewable and Sustainable Energy Reviews, vol. 16, no. 8, p. 5802, 2012.

[10] A. Gil, M. Medrano, I. Martorell et al., "State of the art on high temperature thermal energy storage for power generation," Renewable Sustainable Energy Review, vol. 14, p. 3, 2010.

[11] Y. Shin, D.-I. Yoo, and K. Son, "Development of thermoregulating textile materials with microencapsulated phase change materials (PCM). II. Preparation and application of PCM microcapsules," Journal of Applied Polymer Science, vol. 96, no. 6, p. 2005, 2005.

[12] Q. Zhang, E. Uchaker, S. L. Candelaria, and G. Cao, "Nanomaterials for energy conversion and storage," Chemical Society Reviews, vol. 42, no. 7, p. 3127, 2013.

[13] L. M. Bal and S. N. Naik, "Solar dryer with thermal energy storage systems for drying agricultural food products: a review," Renewable and Sustainable Energy Reviews, vol. 14, no. 8, p. 2298, 2010.

[14] D. C. Satya, N. S. Levinson, U. Jeong, and Y. Xia, "Emerging applications of phase-change materials (PCMs): teaching an old dog new tricks," Angewandte Chemie International Edition, vol. 53, no. 15, p. 3780, 2014.

[15] A. Abhat, "Low temperature latent heat thermal energy storage: heat storage materials," Solar Energy, vol. 30, no. 4, p. 313, 1983.

[16] Y. Cai, C. Gao, T. Zhang et al., "Influences of expanded graphite on structural morphology and thermal performance of composite phase change materials consisting of fatty acid eutectics and electrospun PA6 nanofibrous mats," Renewable Energy, vol. 57, pp. 163-170, 2013.

[17] P. Zhao, Q. Yue, H. He, B. Gao, Y. Wang, and Q. Li, "Study on phase diagram of fatty acids mixtures to determine eutectic temperatures and the corresponding mixing proportions," Applied Energy, vol. 115, pp. 483-490, 2014.

[18] M. Li, H. Kao, Z. Wu, and J. Tan, "Study on preparation and thermal property of binary fatty acid and the binary fatty acids/diatomite composite phase change materials," Applied Energy, vol. 88, no. 5, pp. 1606-1612, 2011.

[19] ASTM D27666-09, Standard Test Method for Specific Heat of Liquids and Solids, ASTM International, West Conshohocken, PA, USA, 2009.

[20] ASTM E87933-06, Standard Test Method for Enthalpies of Fusion and Crystallization by Differential Scanning Calorimetry, ASTM International, West Conshohocken, PA, USA, 2006.

[21] C. R. Raj, S. Suresh, R. R. Bhavsar, V. K. Singh, A. S. Reddy, and A. Upadhyay, "Manganese-based layered perovskite solid-solid phase change material: synthesis, characterization and thermal stability study," Mechanics of Materials, vol. 135, pp. 88-97, 2019.

[22] S. Wi, S. Yang, J. Lee, S. J. Chang, and S. Kim, "Dynamic heat transfer and thermal performance evaluation of PCM-doped hybrid hollow plaster panels for buildings," Journal of Hazardous Materials, vol. 374, pp. 428-436, 2019.

[23] M. S. Mert, H. H. Mert, and C. Yilmaz Gumus, "Preparation and characterization of paraffin microcapsules for energysaving applications," Journal of Applied Polymer Science, vol. 136, no. 33, p. 47874, 2019.

[24] I.-H. Kim, H.-W. Sim, H.-H. Hong, D.-W. Kim, W. Lee, and D.-K. Lee, "Effect of filler size on thermal properties of paraffin/silver nanoparticle composites," Korean Journal of Chemical Engineering, vol. 36, no. 6, pp. 1004-1012, 2019.

[25] S. Azarfar, S. Movahedirad, and A. A. Sarbanha, "Low cost and new design of transient hot-wire technique for the thermal conductivity measurement of fluids," Applied Thermal Engineering, vol. 105, pp. 142-150, 2016.

[26] N. Garti, S. Sarig, and E. Wellner, "Determination of the composition of mixtures of fatty acid polymorphs by DTA," Thermochimica Acta, vol. 37, no. 2, p. 131, 1980.

[27] J. C. van Miltenburg, H. A. J. Oonk, and L. Ventola, "Heat capacities and derived thermodynamic functions of 1-octadecanol, 1-nonadecanol, 1-eicosanol, and 1-docosanol between $10 \mathrm{~K}$ and $370 \mathrm{~K}$," Journal of Chemical \& Engineering Data, vol. 46, no. 1, p. 90, 2001.

[28] F. G. Gandolfo, A. Bot, and E. Flöter, "Phase diagram of mixtures of stearic acid and stearyl alcohol," Thermochimica Acta, vol. 404, no. 1-2, pp. 9-17, 2003.

[29] K. Bhaggan, K. W. Smith, and C. Blecker, "Polymorphism and kinetic behavior of binary mixtures of trisaturated triacylglycerols containing palmitic and stearic acid under nonisothermal conditions," European Journal of Lipid Science and Technology.vol. 120, 2018.

[30] H. Yi, W. Zhan, Y. Zhao et al., "A novel core-shell structural montmorillonite nanosheets/stearic acid composite PCM for great promotion of thermal energy storage properties," Solar Energy Materials and Solar Cells, vol. 192, pp. 57-64, 2019.

[31] D. Mei, B. Zhang, R. Liu, H. Zhang, and J. Liu, "Preparation of stearic acid/halloysite nanotube composite as form-stable PCM for thermal energy storage," International Journal of Energy Research, vol. 35, pp. 828-834, 2019.

[32] A. Sari and K. Kaygusuz, "Thermal performance of a eutectic mixture of lauric and stearic acids as PCM encapsulated in the annulus of two concentric pipes," Solar Energy, vol. 72, no. 6, pp. 493-504, 2002.

[33] X. C. Fu, W. X. Shen, T. Y. Yao et al., Physical Chemistry, Higher Education Press, Beijing, China, 2005. 